\title{
Dulaglutide and Insulin: How Can the AWARD Studies Help Guide Clinical Practice?
}

Richard J. MacIsaac

Received: April 22, 2020 / Published online: June 20, 2020

(c) The Author(s) 2020

\section{ABSTRACT}

The glucagon-like peptide 1 receptor agonist (GLP-1RA) dulaglutide has many characteristics to recommend it both as a second-line agent and as an alternative to or in combination with insulin. This commentary summarises recent updates to diabetes management guidelines regarding the use of GLP-1RAs such as dulaglutide, both as a second-line agent and as a firstline injectable agent in type 2 diabetes (T2D). It also examines how the Assessment of Weekly AdministRation of LY2189265 [dulaglutide] in Diabetes (AWARD) studies with dulaglutide and insulin may help to guide clinical practice for the use of dulaglutide as an alternative to basal insulin or in combination with insulin.

Individualising glucose-lowering therapy is important in patients with T2D, especially given patients' heterogeneity in terms of age,

Digital Features To view digital features for this article go to https://doi.org/10.6084/m9.figshare.12464588.

R. J. MacIsaac ( $\square)$

St Vincent's Hospital, University of Melbourne,

Victoria, Australia

e-mail: r.macisaac@unimelb.edu.au lifestyle, disease duration, level of hyperglycaemia and comorbidities. Choice of therapy should be guided by clinical considerations (e.g. high risk or existing cardiovascular $[\mathrm{CV}]$ disease, heart failure, chronic kidney disease, risk of hypoglycaemia), side effect profile, contraindications, patient preferences and cost. The recently updated American Diabetes Association/European Association for the Study of Diabetes (ADA/EASD) guidelines now recommend adding a GLP-1RA with proven CV benefit to metformin in patients with T2D and indicators of high risk or established atherosclerotic CV disease. The AWARD studies demonstrate that dulaglutide provides effective glucose lowering together with sustained weight loss and a low incidence of hypoglycaemia when used as the first injectable option and when used in combination with titrated basal insulin or prandial insulin, providing a valid treatment option across a wide range of patients with T2D, including those with chronic kidney disease.

Keywords: AWARD studies; Dulaglutide; Insulin; Type 2 diabetes 


\section{Key Summary Points}

This commentary summarises recent updates to diabetes management guidelines regarding the use of glucagonlike peptide 1 receptor agonists such as dulaglutide, both as a second-line agent and as a first-line injectable agent in type 2 diabetes. It also provides practical guidance on the use of dulaglutide as an alternative to basal insulin or in combination with insulin by examining the AWARD (Assessment of Weekly AdministRation of LY2189265 [dulaglutide] in Diabetes) studies.

The AWARD studies demonstrate that dulaglutide provides effective glucose lowering together with sustained weight loss and a low incidence of hypoglycaemia when used as the first injectable option and when used in combination with titrated basal insulin or prandial insulin.

The broad range of patients enrolled in the AWARD studies reflect the heterogeneity of the general population of patients with type 2 diabetes, and demonstrate that dulaglutide is a valid treatment option across a wide range of patient characteristics, including different levels of hyperglycaemia, glycaemic patterns, prior oral antidiabetic therapies, age and duration of diabetes, and presence of comorbidities.

Most patients enrolled in AWARD-9 reported that the standard dulaglutide injection device used in the study and in clinical practice was "easy" or "very easy", and $90 \%$ were satisfied with the overall injection experience.

\section{INTRODUCTION}

Glucagon-like peptide 1 receptor agonists (GLP1RAs) such as dulaglutide act by increasing glucose-dependent insulin secretion, decreasing glucagon release, and slowing gastric emptying. They also inhibit hepatic glucose production and suppress appetite [1-3]. These properties provide effective glucose lowering with a low risk of hypoglycaemia and promote weight loss in patients with type 2 diabetes (T2D) [1-3].

Although the benefits of GLP-1RAs such as dulaglutide are generally well recognised, their place in the overall management of T2D, and where they fit into a management plan for individual patients, may be less familiar-especially given recent updates to diabetes management guidelines [4-6]. This commentary evaluates recently updated treatment algorithms covering the use of GLP-1RAs in T2D. It also aims to provide practical guidance on the use of dulaglutide as an alternative to basal insulin or in combination with insulin, by examining the Assessment of Weekly AdministRation of LY2189265 [dulaglutide] in Diabetes (AWARD) studies that investigated the use of dulaglutide and insulin across a broad range of patients with T2D [7-11]. This article is based on previously conducted studies and does not contain any studies with human participants or animals performed by the author.

\section{GUIDELINE RECOMMENDATIONS FOR GLP-1RAS IN T2D}

Choice of glucose-lowering agents in T2D should be guided by clinical considerations (e.g. presence or high risk of cardiovascular [CV] disease, heart failure, chronic kidney disease, hypoglycaemia), side effect profile, contraindications, patient preference and cost [6]. GLP1RAs such as dulaglutide may be considered second-line (e.g. as add-on therapy to metformin), or as the first injectable option added to two or three oral antidiabetic agents [4-6]. 


\section{Early Use of GLP-1RAs}

Cardiovascular outcomes studies with the GLP1RAs dulaglutide (REWIND study) [12, 13], liraglutide (LEADER) [14, 15] and semaglutide (SUSTAIN-6) [16] have demonstrated cardioand renal protection in patients with T2D who have established CV disease (LEADER, SUSTAIN6) [14-16] and/or are at high risk of CV events (REWIND) [12, 13]. Accordingly, the most recent (2020) update of the American Diabetes Association/European Association for the Study of Diabetes (ADA/EASD) guidelines recommend adding a GLP-1RA with proven CV benefit to metformin for patients with indicators of high risk or established atherosclerotic CV disease $[4,5]$. They further suggest that the decision to treat should be considered regardless of whether glycated haemoglobin $\left(\mathrm{HbA}_{1 \mathrm{c}}\right)$ is at target $[4,5]$. GLP-1RAs are also recommended as the first or second add-on option to metformin for patients above target $\mathrm{HbA}_{1 \mathrm{c}}$ who have a compelling need to minimise hypoglycaemia or to minimise weight gain/promote weight loss [4, 5].

Other recently updated guidelines, such as the 2020 Australian Diabetes Society (ADS) treatment algorithm, also highlight the potential for improved major adverse CV endpoints (MACE) when agents with proven CV benefit are used in patients at high risk for the development of CV disease or in those with established CV disease [6].

\section{GLP-1RAs and Insulin}

Numerous reviews and meta-analyses have reported on the use of GLP-1RAs as an alternative to basal insulin or in combination with either a basal or prandial insulin [3, 17-23], and it is beyond the scope of this article to compare and contrast data for individual GLP-1RAs vs insulin. Overall, the data support the ADA/ EASD guideline recommendation that GLP1RAs are introduced as the first injectable option for most patients with T2D who require an injectable therapy, as GLP-1RAs are associated with a lower risk of hypoglycaemia and beneficial effects on bodyweight compared with insulin [4, 24]. However, insulin should still be considered as a first injectable if there is evidence of ongoing catabolism (weight loss), if symptoms of hyperglycaemia are present, when $\mathrm{HbA}_{1 \mathrm{c}}$ or blood glucose levels are very high $\left(\mathrm{HbA}_{\mathrm{c}}>10 \% \quad[86 \mathrm{mmol} / \mathrm{mol}]\right.$, blood glucose $>16.7 \mathrm{mmol} / \mathrm{L}$ ), if a diagnosis of type 1 diabetes is possible, or if patients are unable to tolerate a GLP-1RA or express a preference for insulin $[4,24]$.

Of note, it has recently been suggested that the early initiation of basal insulin should be considered in patients with $\mathrm{HbA}_{1 \mathrm{c}}>9.0 \%$, as opposed to the current recommendation of $>10 \%$, to better reduce immediate metabolic risks and subsequent associated long-term complications of hyperglycaemia [25].

As T2D progresses, many patients will eventually require insulin, and guidelines recommend adding a basal insulin to a GLP-1RA if $\mathrm{HbA}_{1 \mathrm{c}}$ is above target $[4,24]$.

\section{DULAGLUTIDE AND INSULIN IN THE AWARD STUDIES}

The AWARD studies described here demonstrate the wide range of patients for whom the onceweekly GLP-1RA dulaglutide may be considered as an alternative or in combination with insulin (Table 1) [7-11, 18]. The summaries below focus on data for dulaglutide $1.5 \mathrm{mg}$, the dose used most commonly worldwide.

\section{Dulaglutide vs Basal Insulin as a First Injectable Option (AWARD-2) [7]}

AWARD-2 investigated the use of once-weekly dulaglutide as an alternative to basal insulin for patients not at glycaemic target on oral therapy [7]. The 78-week open-label, randomised, multicentre, non-inferiority study compared onceweekly dulaglutide $(1.5 \mathrm{mg}$ or $0.75 \mathrm{mg}$ ) with daily insulin glargine (U 100) in patients receiving maximally tolerated doses of metformin and glimepiride. The main outcome measure for this study was to demonstrate noninferiority of dulaglutide $1.5 \mathrm{mg}$ to glargine in the $\mathrm{HbA}_{1 \mathrm{c}}$ change from baseline at 52 weeks. 


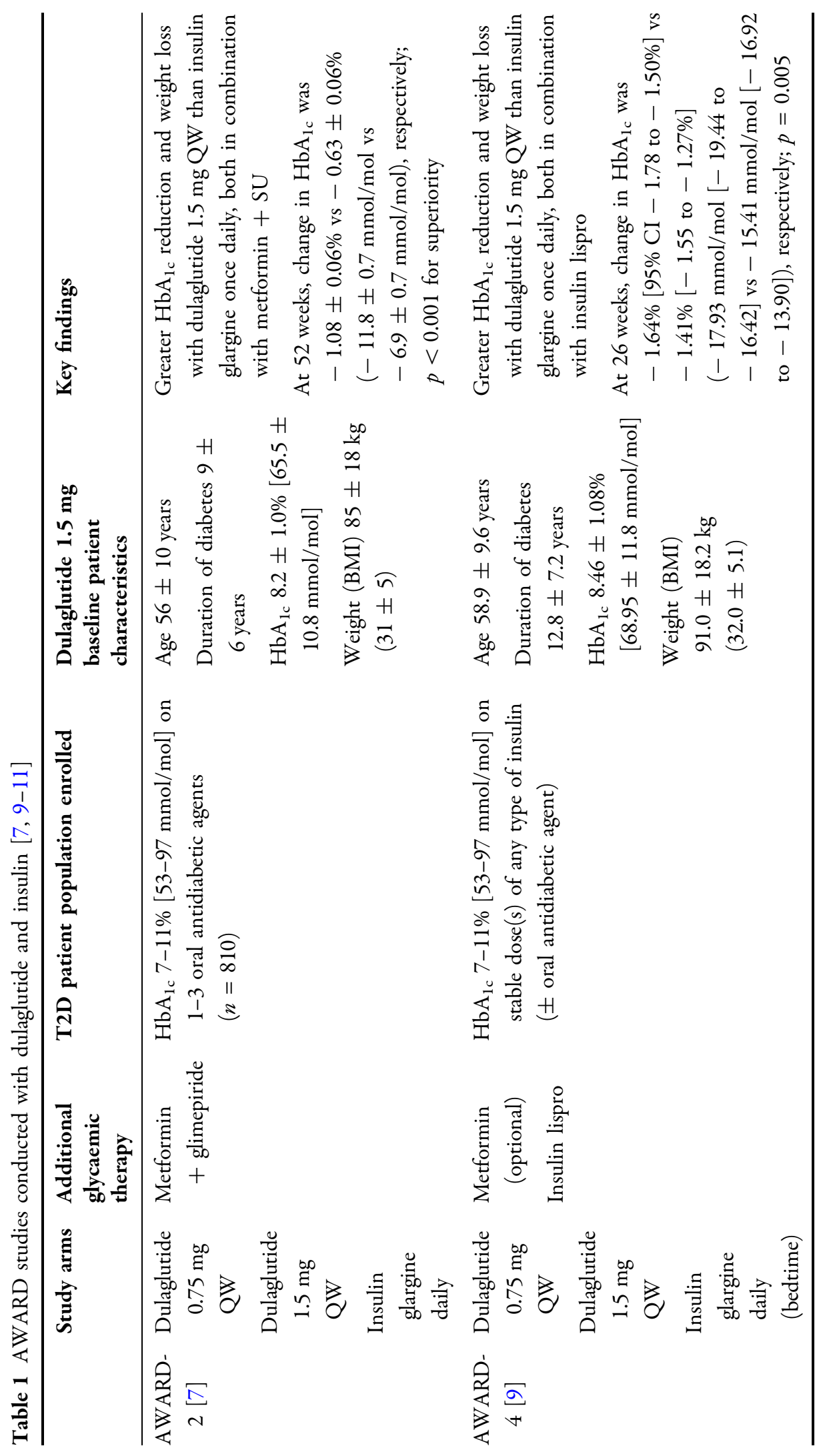




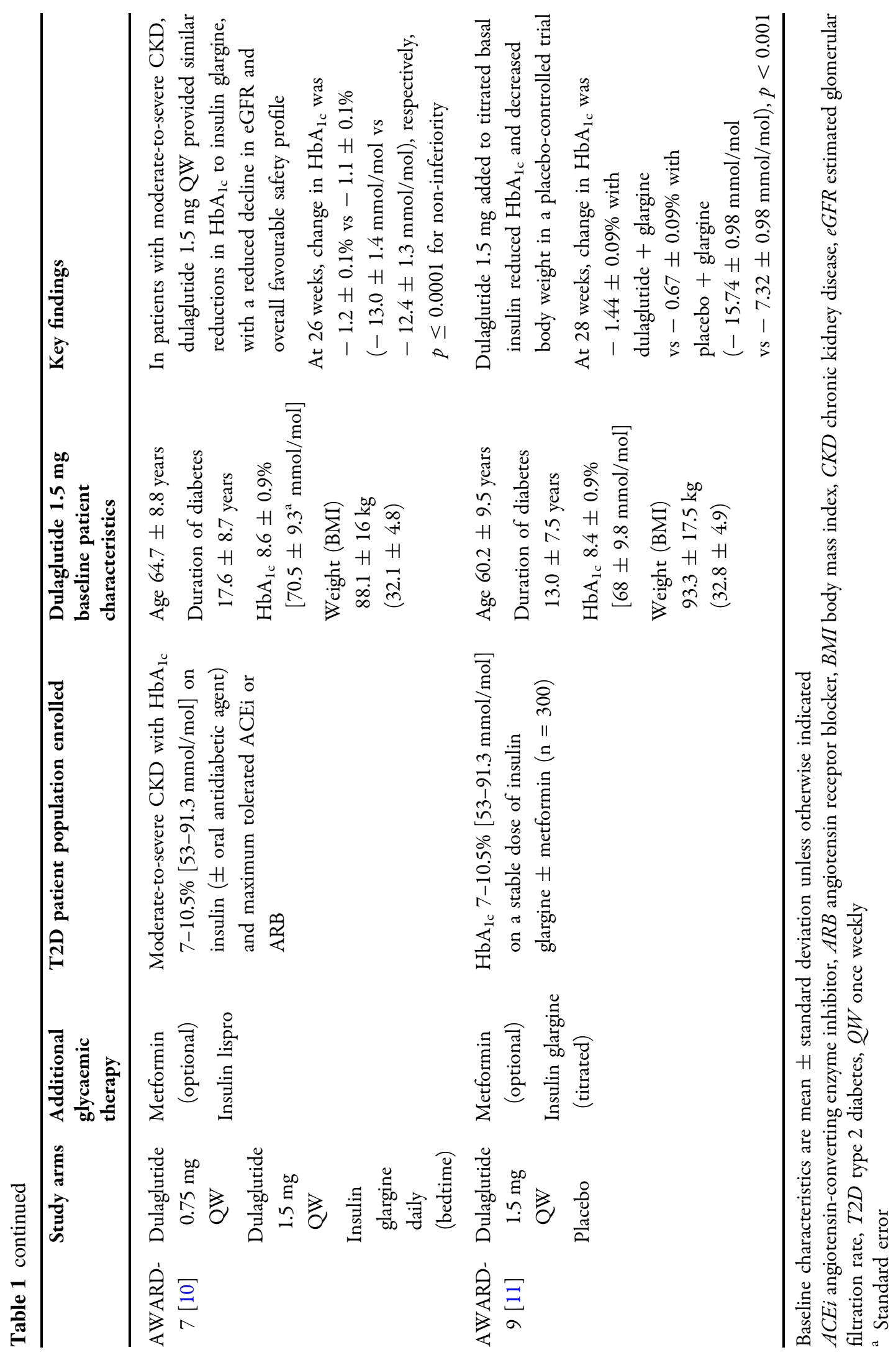


Enrolled patients were naïve to injectable diabetes therapy. Insulin glargine was initiated at 10 units once daily; patients were instructed to adjust insulin doses according to a standard titration algorithm with target fasting plasma glucose $(\mathrm{FPG})<5.6 \mathrm{mmol} / \mathrm{L}$, although titration to euglycaemia was not achieved by most patients [7].

Dulaglutide $1.5 \mathrm{mg}$ was not only found to be non-inferior but also found to be superior to insulin glargine at both 52 and 78 weeks $(p<0.001)$. $\mathrm{HbA}_{1 \mathrm{c}}$ change from baseline to 52 weeks was $\quad-1.08 \pm 0.06 \%$ $[-11.8 \pm 0.7 \mathrm{mmol} / \mathrm{mol}]$ with dulaglutide $1.5 \mathrm{mg} \quad$ and $\quad-0.63 \pm 0.06 \%$ $[-6.9 \pm 0.7 \mathrm{mmol} / \mathrm{mol}]$ with insulin glargine. Over half $(53.2 \%)$ of patients receiving dulaglutide $1.5 \mathrm{mg}$ achieved $\mathrm{HbA}_{1 \mathrm{c}}<7.0 \%$ $[<53 \mathrm{mmol} / \mathrm{mol}]$ at 52 weeks, compared with $30.9 \%$ of patients receiving insulin glargine. Post hoc analysis demonstrated greater $\mathrm{HbA}_{1 \mathrm{c}}$ reductions with dulaglutide $1.5 \mathrm{mg}$ regardless of baseline glycaemic pattern (high or low FPG and postprandial glucose) [8]. Dulaglutide was associated with weight loss, whereas patients on insulin glargine gained weight $(-1.87 \pm 0.24 \mathrm{~kg}$ with dulaglutide $1.5 \mathrm{mg}$, and $+1.44 \pm 0.24 \mathrm{~kg}$ with insulin glargine at 52 weeks, $p<0.001)$.

Nocturnal hypoglycaemia was significantly more frequent with insulin glargine than with dulaglutide $1.5 \mathrm{mg}(p<0.001)$, whereas gastrointestinal adverse events such as nausea, diarrhoea and vomiting were significantly more frequent with dulaglutide $(p<0.05)$.

\section{Dulaglutide vs Basal Insulin, Both in Combination with Insulin Lispro (AWARD-4) [9]}

Few studies have examined the potential of combining a GLP-1RA with prandial insulin as an option for intensifying therapy in T2D. AWARD-4 was a randomised, open-label, noninferiority study comparing a basal-bolus insulin regimen with dulaglutide plus mealtime insulin. Patients with inadequately controlled $\mathrm{HbA}_{1 \mathrm{c}}$ on their current insulin regimen $(n=884)$ received dulaglutide $1.5 \mathrm{mg}$ once weekly (QW), dulaglutide $0.75 \mathrm{mg} \mathrm{QW}$, or insulin glargine (daily at bedtime), all in combination with mealtime insulin lispro. Insulin glargine and lispro doses were adjusted according to a titration algorithm. The primary endpoint was $\mathrm{HbA}_{1 \mathrm{c}}$ at 52 weeks.

Dulaglutide $1.5 \mathrm{mg}$ plus insulin lispro resulted in significantly greater reductions in $\mathrm{HbA}_{1 \mathrm{c}}$ at 26 weeks than insulin glargine plus insulin lispro ( $-1.64 \%$ [95\% CI -1.78 to $-1.50 \%]$ vs $-1.41 \%$ [- 1.55 to $-1.27 \%]$ or $-17.93 \mathrm{mmol} / \mathrm{mol}$ [- 19.44 to -16.42$]$ vs $-15.41 \mathrm{mmol} / \mathrm{mol} \quad[-16.92$ to -13.90$]$; $p=0.005)$, with differences sustained over 52 weeks. Significantly more patients achieved $\mathrm{HbA}_{1 \mathrm{c}}<7 \%[<53 \mathrm{mmol} / \mathrm{mol}]$ at 26 weeks in the dulaglutide $1.5 \mathrm{mg}$ group than the insulin glargine group $(p=0.014)$. Weight loss occurred in the dulaglutide $1.5 \mathrm{mg}$ group $(-1.87 \mathrm{~kg}$ [ -1.40 to -0.34$]$ at week 26$)$, compared with weight gain with insulin glargine $(2.33 \mathrm{~kg}$ [1.80-2.86]), $p<0.001$; differences were sustained over 52 weeks.

The most frequent adverse events, which occurred significantly more often with dulaglutide than insulin glargine, were nausea, diarrhoea and vomiting. Gastrointestinal events were mostly mild to moderate and most resolved within the first 4-6 weeks. The rates of total hypoglycaemia and nocturnal hypoglycaemia were significantly lower with dulaglutide $1.5 \mathrm{mg}$ than with insulin glargine $(p<0.001$ at week 26).

\section{Dulaglutide in Patients with Moderate-to- Severe Chronic Kidney Disease (AWARD-7) [10]}

Chronic kidney disease (CKD) increases the complexity and risks of diabetes management. Treatment options for hyperglycaemia are limited in moderate-to-severe CKD (CKD stages 3-4), as many glucose-lowering agents, including insulin, are primarily cleared by the kidneys. Patients frequently require dose adjustments to their glucose-lowering medications and are at an increased risk of hypoglycaemia due to reduced drug clearance and 
impaired gluconeogenesis by the kidney $[10,26]$.

AWARD-7 was the first study of a GLP-1 receptor agonist to specifically enrol a large number of participants with moderate-to-severe CKD. The open-label study randomised patients with moderate-to-severe CKD $(n=576$, mean duration of T2D 18 years) to dulaglutide $1.5 \mathrm{mg}$ QW, dulaglutide $0.75 \mathrm{mg}$ QW or insulin glargine (daily at bedtime). All patients received mealtime insulin lispro and were on maximum tolerated angiotensin-converting enzyme inhibitor or angiotensin receptor blocker. Insulin glargine and lispro doses were adjusted according to a titration algorithm specific for people with CKD. The primary endpoint was $\mathrm{HbA}_{1 \mathrm{c}}$ at 26 weeks; secondary endpoints included estimated glomerular filtration rate (eGFR) and urine albumin-to-creatinine ratio (UACR) [10].

$\mathrm{HbA}_{1 \mathrm{c}}$ was reduced with both dulaglutide $1.5 \mathrm{mg}$ and insulin glargine $(-1.2 \pm 0.1 \%$ $[-13.0 \pm 1.4 \mathrm{mmol} / \mathrm{mol}]$ and $-1.1 \pm 0.1 \%$ $[-12.2 \pm 1.3 \mathrm{mmol} / \mathrm{mol}]$, respectively at week 26; $p \leq 0.0001$ for non-inferiority), with reductions sustained over 52 weeks. Analysis of secondary endpoints demonstrated no change in eGFR with dulaglutide $1.5 \mathrm{mg}$ at 26 and 52 weeks, whereas eGFR declined in the insulin glargine group; thus at 52 weeks, eGFR was significantly higher for patients treated with dulaglutide $1.5 \mathrm{mg}$ than with insulin glargine $(p<0.001)$. Decreases in UACR were seen in all treatment groups; significantly greater reductions in UACR occurred with dulaglutide $1.5 \mathrm{mg}$ vs insulin glargine in patients with macroalbuminuria at baseline (week 26: - 43.1\% [95\% CI 54.7-28.6] vs - 14.3\% [30.9-6.3], $p=0.008$; macroalbuminuria defined as UACR $>300 \mathrm{mg} /$ g). Dulaglutide was also associated with a reduction in body weight vs insulin glargine $(p<0.001$ at 26 weeks, sustained over 52 weeks). Insulin lispro doses increased from baseline to week 26 , and were similar between the dulaglutide $1.5 \mathrm{mg}$ and insulin glargine groups [10].

Hypoglycaemia (total, documented symptomatic and nocturnal) occurred less frequently with dulaglutide than with insulin glargine; no patients in the dulaglutide $1.5 \mathrm{mg}$ group experienced severe hypoglycaemia vs 13 (7\%) in the insulin glargine group $(p=0.0003)$. Incidence of serious adverse events and adverse events for kidney disease did not differ between treatment groups, but higher rates of nausea and diarrhoea were observed with dulaglutide than with insulin glargine [10].

In summary, despite achieving similar reductions in $\mathrm{HbA}_{1 \mathrm{c}}$ with dulaglutide or insulin in CKD patients, the use of dulaglutide in this study was associated with less hypoglycaemia, more weight loss and better measures of kidney health compared with glargine.

\section{Dulaglutide Added to Titrated Basal Insulin (AWARD-9) [11]}

Treat-to-target (TTT) dosing algorithms are designed to optimise insulin therapy while minimising the risk of hypoglycaemia. Yet poorly optimised or delayed titration of basal insulin is common, and can lead to suboptimal glycaemic control [11, 27]. AWARD-9 assessed the addition of once-weekly dulaglutide to an optimised TTT basal insulin regimen, to determine the effect on glycaemic control, insulin dose, hypoglycaemia, body weight and patient-reported outcomes [11]. In the double-blind, placebo-controlled study, all patients received insulin glargine with intensive TTT titration, and were randomised to placebo or dulaglutide $1.5 \mathrm{mg} \mathrm{QW}$. The primary endpoint was change in $\mathrm{HbA}_{1 \mathrm{c}}$ from baseline to week 28 [11].

In patients receiving titrated insulin glargine, addition of dulaglutide $1.5 \mathrm{mg}$ QW vs placebo resulted in significantly greater reduction in $\mathrm{HbA}_{1 \mathrm{c}}(-1.44 \pm 0.09 \%[-15.74 \pm$ $0.98 \mathrm{mmol} / \mathrm{mol}]$ vs $-0.67 \pm 0.09 \%[-7.32 \pm$ $0.98 \mathrm{mmol} / \mathrm{mol}] ; p<0.001)$, significantly more patients with $\mathrm{HbA}_{1 \mathrm{c}}<7 \% \quad[53 \mathrm{mmol} / \mathrm{mol}]$ $(66.7 \%$ vs $33.3 \% ; \quad p<0.001)$, significantly reduced body weight $(-1.91 \pm 0.30 \mathrm{~kg}$ vs + $0.50 \pm 0.30 \mathrm{~kg} ; \quad p<0.001)$ and significantly smaller increases in basal insulin dose $(13 \pm 2 \mathrm{U}$ vs $26 \pm 2 \mathrm{U} ; p<0.001$ ) [11].

Incidence of hypoglycaemia was similar for the dulaglutide and placebo groups. Gastrointestinal adverse events occurred more often in dulaglutide-treated patients, including nausea 
(12.0\%), diarrhoea (11.3\%) and vomiting (6.0\%). The study concluded that combination of once-weekly dulaglutide $1.5 \mathrm{mg}$ with basal insulin glargine provides an effective and safe treatment option for patients with T2D already treated with basal insulin but who have hyperglycaemia and $\mathrm{HbA}_{1 \mathrm{c}}$ levels above their target range [11].

\section{DULAGLUTIDE SAFETY AND PATIENT CONSIDERATIONS}

Incidence of hypoglycaemia is an essential consideration for patients with T2D; even mild episodes of hypoglycaemia can affect an individual's quality of life, and fear of hypoglycaemia may lead to reduced adherence or underutilisation of insulin $[28,29]$. The consistently lower rates of hypoglycaemia reported with dulaglutide compared with insulin are therefore of important clinical significance, particularly given the improved glycaemic control with dulaglutide [7].

The most common adverse events reported with dulaglutide, as with other GLP-1RAs, are gastrointestinal disorders such as nausea, diarrhoea and vomiting [7, 9-11, 30]. Patients should be counselled about these potential side effects before starting therapy, with advice on how to mitigate them. For example, stopping eating when full or reducing food intake may aid GLP-1RA-associated nausea and vomiting [31]. Gastrointestinal adverse events with dulaglutide are generally mild or moderate in severity, peak during the first 2 weeks of treatment then rapidly decline over the next 4 weeks and rarely lead to treatment discontinuation [32-34]. Other reported adverse events with dulaglutide include a small mean increase in heart rate, small decrease in systolic blood pressure and increases in pancreatic enzymes [7, 9-11]. Rapid improvement in glucose control has been associated with a temporary worsening of diabetic retinopathy; in the REWIND cardiovascular outcomes study with dulaglutide, diabetic retinopathy complications were reported in patients with a history of diabetic retinopathy at baseline (dulaglutide $8.5 \%$, placebo 6.2\%) [34]. An increase in diabetic retinopathy has also been reported with the use of semaglutide in the SUSTAIN-6 trial, with a mediation analysis suggesting that a worsening of diabetic retinopathy was only seen in semaglutide-treated patients who experienced a rapid improvement in blood glucose levels [35]. To date, there is no evidence that the GLP-1RA class has any direct deleterious effect on the development or progression of diabetic retinopathy [36].

Personalising therapy to reflect patients' practical and emotional (as well as clinical) needs is likely to improve acceptance, which may help overcome therapeutic inertia and improve adherence [37, 38]. Patient-reported outcomes (PROs) from the AWARD clinical trials demonstrate significantly greater improvements with dulaglutide $1.5 \mathrm{mg}$ vs insulin glargine in weight-related scores (Impact of Weight on Self-Perception [IW-SP] and Impact of Weight on Ability to Perform Physical Activities of Daily Living [APPADL]) [11, 39]. AWARD-2, comparing dulaglutide vs insulin glargine in patients receiving metformin plus glimepiride, also demonstrated significant improvements in the EQ-5D UK Index (a standardised measure of general health status/ health-related quality of life; $p=0.001$ ) and Adult Low Blood Sugar Survey scores (total score, $p=0.003$; worry subscale, $p=0.003$; behaviour subscale, $p=0.038$ ) for the dulaglutide $1.5 \mathrm{mg}$ arm compared with the insulin glargine arm [39]. Most patients enrolled in AWARD-9 reported that the standard dulaglutide injection device used in the study and in clinical practice was "easy" or "very easy", and $90 \%$ were satisfied with the overall injection experience. Features relating to the dulaglutide injection device that were rated highly included not having to touch the needle, not having to attach the needle, and automatic insertion [11]. Small-scale studies comparing PROs with dulaglutide vs other GLP-1RAs report treatment satisfaction with dulaglutide [40, 41]. Further larger-scale studies to examine PROs with dulaglutide would be of interest. 


\section{AVOIDING THERAPEUTIC INERTIA}

Therapeutic or clinical inertia is the failure to advance or intensify therapy when appropriate to do so [42]. To avoid therapeutic inertia, guidelines recommend reviewing glycaemic control every 3-6 months, and intensifying treatment (moving down the treatment algorithm) if indicated $[4,6]$. But therapeutic inertia is common over the course of diabetes management, and is particularly prevalent when initiating or titrating insulin [42-47]. Indeed, therapeutic inertia may have contributed to suboptimal use of basal insulin the AWARD-2 clinical trial. Although participants in the study were provided with an insulin titration algorithm, there was no central oversight of dose titration and basal insulin was not titrated to fasting euglycaemia in most patients [7]. If basal insulin dose is not optimised under clinical trial conditions, it seems unlikely to be optimised by busy clinicians in real-world settings.

Insulin inertia is a complex area with many contributing factors, including patient- and/or physician-driven concerns about hypoglycaemia, weight gain and adherence to burdensome regimens [46]. The risks (e.g. hypoglycaemia, weight gain) and benefits (improved glycaemic control) associated with insulin are considered every time the dose is adjusted, and the ideal balance may be difficult to achieve. Although it is beyond the scope of this article to discuss therapeutic inertia in detail (refer to Russell-Jones et al. [46] for a practical review of barriers to insulin therapy), it is possible to speculate that a GLP-1RA such as once-weekly dulaglutide offers several features that may help overcome common barriers to initiating an injectable agent. Dulaglutide is associated with weight loss rather than weight gain, and incidence of hypoglycaemia is generally lower than is seen with basal insulin $[7,10,18]$. Moreover, dulaglutide has a simple dosing regimen, with a lower injection burden than basal insulin (i.e. weekly vs daily injections), does not require titration to target, and is administered via a ready-to-use device with a 'hidden' pre-attached needle [2, 11, 32, 48].

\section{KEY PRACTICE POINTS}

Diabetes management guidelines recommend that all treatment decisions are timely, evidence-based and are made collaboratively with patients on the basis of individual preferences, prognoses and comorbidities [4]. Personalised therapy is particularly important given the heterogeneity of patients with T2D in terms of age, lifestyle, disease duration, level of hyperglycaemia and comorbidities [3, 49].

The AWARD studies demonstrate that dulaglutide is well tolerated and effective when used:

- As the first injectable option (as an alternative to basal insulin)

- In combination with insulin lispro (as an alternative to a basal-bolus insulin regimen)

- In combination with titrated basal insulin (as an add-on therapy to optimised basal insulin)

- In patients with CKD

The broad range of patients enrolled in the AWARD clinical trials reflect the heterogeneity of the general population of patients with type 2 diabetes, and demonstrate that dulaglutide is a valid treatment option across a wide range of patient characteristics (Table 1), including different:

- Levels of hyperglycaemia [7, 9-11, 50]

- Glycaemic patterns (high or low fasting blood glucose and post-prandial glucose) [8]

- Prior oral antidiabetic therapies $[7,9,18]$

- Age and duration of diabetes [7, 9-11, 50] (although therapeutic experience in people aged $\geq 75$ years is limited)

- Comorbidities, including moderate-to-severe CKD and CV disease $[10,12]$

- Insulin naïve or experienced [7, 9-11]

Clinical benefits, ease of administration and device features may all contribute towards patient and clinician satisfaction with a treatment. Dulaglutide provides effective glucose lowering together with sustained weight loss and a low incidence of hypoglycaemia. It also offers the convenience of once-weekly administration without the need for dose titration, and is supplied in a pre-filled injection device 
with a 'hidden' needle that is easy for people with T2D to use. As with all GLP-1RAs, the most common gastrointestinal adverse events are generally mild to moderate and decrease over time; patient counselling may help to mitigate these side effects. Overall, dulaglutide offers a safe and convenient treatment option for people with type 2 diabetes.

\section{ACKNOWLEDGEMENTS}

Funding. This article and the journals' Rapid Service Fee were funded by Eli Lilly Australia. The author had full access to the articles reviewed in this manuscript and takes complete responsibility for the integrity and accuracy of this manuscript.

Medical Writing Assistance. Editorial assistance in the preparation of this article was provided by Dr. Sue Cripps of McCann Health, Australia. Support for this assistance was funded by Eli Lilly Ltd.

Authorship. The named author meets the International Committee of Medical Journal Editors (ICMJE) criteria for authorship for this article, takes responsibility for the integrity of the work as a whole, and has given approval for this version to be published.

Disclosures. Richard MacIsaac has received speaker fees and travel support from Eli Lilly Australia, and is also on the national advisory board for Eli Lilly Australia.

Compliance with Ethics Guidelines. This article is based on previously conducted studies and does not contain any studies with human participants or animals performed by the author.

Data Availability. Data sharing is not applicable to this article as no datasets were generated or analysed during the current study.

Open Access. This article is licensed under a Creative Commons Attribution-
NonCommercial 4.0 International License, which permits any non-commercial use, sharing, adaptation, distribution and reproduction in any medium or format, as long as you give appropriate credit to the original author(s) and the source, provide a link to the Creative Commons licence, and indicate if changes were made. The images or other third party material in this article are included in the article's Creative Commons licence, unless indicated otherwise in a credit line to the material. If material is not included in the article's Creative Commons licence and your intended use is not permitted by statutory regulation or exceeds the permitted use, you will need to obtain permission directly from the copyright holder. To view a copy of this licence, visit http:// creativecommons.org/licenses/by-nc/4.0/.

\section{REFERENCES}

1. Kugler AJ, Thiman ML. Efficacy and safety profile of once-weekly dulaglutide in type 2 diabetes: a report on the emerging new data. Diabetes Metab Syndr Obes. 2018;11:187-97.

2. Rasalam R, Barlow J, Kennedy M, Phillips P, Wright A. GLP-1 receptor agonists for type 2 diabetes and their role in primary care: an Australian perspective. Diabetes Ther. 2019;10:1205-17.

3. Romera I, Cebrián-Cuenca A, Álvarez-Guisasola F, Gomez-Peralta F, Reviriego J. A review of practical issues on the use of glucagon-like peptide- 1 receptor agonists for the management of type 2 diabetes. Diabetes Ther. 2019;10:5-19.

4. American Diabetes Association. Standards of medical care in diabetes-2020 abridged for primary care providers. Clin Diabetes. 2020;38:10-38.

5. Buse JB, Wexler DJ, Tsapas A, et al. Update to: management of hyperglycemia in type 2 diabetes, 2018. A consensus report by the American Diabetes Association (ADA) and the European Association for the Study of Diabetes (EASD). Diabetes Care. 2019;2020(43):487-93.

6. Australian Diabetes Society. Australian type 2 diabetes management algorithm. https://t2d. diabetessociety.com.au/documents/4tuVr56d.pdf. Accessed Jan 30, 2020. 
7. Giorgino F, Benroubi M, Sun J-H, Zimmermann AG, Pechtner V. Efficacy and safety of once-weekly dulaglutide vs insulin glargine in patients with type 2 diabetes on metformin and glimepiride (AWARD-2). Diabetes Care. 2015;38:2241-9.

8. Giorgino F, Yu M, Haupt A, Milicevic Z, GarcíaPérez L. Effect of once-weekly dulaglutide vs insulin glargine in people with type 2 diabetes and different baseline glycaemic patterns: a post hoc analysis of the AWARD-2 clinical trial. Diabetes Obes Metab. $2019 ; 21: 2570-5$.

9. Blonde L, Jendle J, Gross J, et al. Once-weekly dulaglutide vs bedtime insulin glargine, both in combination with prandial insulin lispro, in patients with type 2 diabetes (AWARD-4): a randomised, open-label, phase 3, non-inferiority study. Lancet. 2015;385:2057-66.

10. Tuttle KR, Lakshmanan MC, Rayner B, et al. Dulaglutide vs insulin glargine in patients with type 2 diabetes and moderate-to-severe chronic kidney disease (AWARD-7): a multicentre, open-label, randomised trial. Lancet Diabetes Endocrinol. 2018;6:605-17.

11. Pozzilli P, Norwood P, Jódar E, et al. Placebo-controlled, randomized trial of the addition of onceweekly glucagon-like peptide-1 receptor agonist dulaglutide to titrated daily insulin glargine in patients with type 2 diabetes (AWARD-9). Diabetes Obes Metab. 2017;19:1024-31.

12. Gerstein HC, Colhoun HM, Dagenais GR, et al. Dulaglutide and cardiovascular outcomes in type 2 diabetes (REWIND): a double-blind, randomised placebo-controlled trial. Lancet. 2019;394:121-30.

13. Gerstein HC, Colhoun HM, Dagenais GR, et al. Dulaglutide and renal outcomes in type 2 diabetes: an exploratory analysis of the REWIND randomised, placebo-controlled trial. Lancet. 2019;394:131-8.

14. Marso SP, Daniels GH, Brown-Frandsen K, et al. Liraglutide and cardiovascular outcomes in type 2 diabetes. N Engl J Med. 2016;375:311-22.

15. Mann JFE, Ørsted DD, Brown-Frandsen K, et al. Liraglutide and renal outcomes in type 2 diabetes. N Engl J Med. 2017;377:839-48.

16. Marso SP, Bain SC, Consoli A, et al. Semaglutide and cardiovascular outcomes in patients with type 2 diabetes. N Engl J Med. 2016;375:1834-44.

17. Singh S, Wright EE, Kwan AYM, et al. Glucagon-like peptide-1 receptor agonists compared with basal insulins for the treatment of type 2 diabetes mellitus: a systematic review and meta-analysis. Diabetes Obes Metab. 2017;19:228-38.
18. Patel H, Munir K, Sutherland S, Karanikas CA, Konig M. Efficacy of dulaglutide as a first injectable option for patients with type 2 diabetes: a post-hoc pooled analysis. Diabetes Ther. 2019;10: 2321-30.

19. Levin PA, Nguyen H, Wittbrodt ET, Kim SC. Glucagon-like peptide- 1 receptor agonists: a systematic review of comparative effectiveness research. Diabetes Metab Syndr Obes. 2017;10:123-39.

20. Meece J. Basal insulin intensification in patients with type 2 diabetes: a review. Diabetes Ther. 2018;9:877-90.

21. Castellana M, Cignarelli A, Brescia F, Laviola L, Giorgino F. GLP-1 receptor agonist added to insulin vs basal-plus or basal-bolus insulin therapy in type 2 diabetes: a systematic review and metaanalysis. Diabetes/Metab Res Rev. 2019;35:e3082.

22. Wysham CH, Lin J, Kuritzky L. Safety and efficacy of a glucagon-like peptide-1 receptor agonist added to basal insulin therapy vs basal insulin with or without a rapid-acting insulin in patients with type 2 diabetes: results of a meta-analysis. Postgrad Med. 2017;129:436-45.

23. Abd El Aziz MS, Kahle M, Meier JJ, Nauck MA. A meta-analysis comparing clinical effects of short- or long-acting GLP-1 receptor agonists vs insulin treatment from head-to-head studies in type 2 diabetic patients. Diabetes Obes Metab. 2017;19: 216-27.

24. American Diabetes Association. 9. Pharmacologic approaches to glycemic treatment: standards of medical care in diabetes-2020. Diabetes Care. 2020;43:S98-110.

25. Hirsch IB, Gaudiani LM. Using insulin to treat poorly controlled type 2 diabetes in 2020. JAMA. 2020. https://doi.org/10.1001/jama.2020.1303.

26. Tuttle KR, Bakris GL, Bilous RW, et al. Diabetic kidney disease: a report from an ADA consensus conference. Diabetes Care. 2014;37:2864-83.

27. Berard L, Bonnemaire $\mathrm{M}$, Mical M, Edelman S. Insights into optimal basal insulin titration in type 2 diabetes: results of a quantitative survey. Diabetes Obes Metab. 2018;20:301-8.

28. Peyrot M, Barnett AH, Meneghini LF, SchummDraeger P-M. Insulin adherence behaviours and barriers in the multinational Global Attitudes of Patients and Physicians in Insulin Therapy study. Diabet Med. 2012;29:682-9.

29. Blumer I, Clement M. Type 2 diabetes, hypoglycemia, and basal insulins: ongoing challenges. Clin Ther. 2017;39:S1-. 
30. Sun F, Chai S, Yu K, et al. Gastrointestinal adverse events of glucagon-like peptide-1 receptor agonists in patients with type 2 diabetes: a systematic review and network meta-analysis. Diabetes Technol Ther. 2015; 17:35-42.

31. Hinnen D. Glucagon-like peptide 1 receptor agonists for type 2 diabetes. Diabetes Spectr. 2017;30: 202-10.

32. Trulicity approved Product Information, July 2019.

33. Trulicity Summary of Product Characteristics. https://www.ema.europa.eu/en/documents/ product-information/trulicity-epar-productinformation_en.pdf. Accessed May 26, 2020.

34. Trulicity (dulaglutide) Prescribing Information. https://uspl.lilly.com/trulicity/trulicity.html\#s20. Accessed May 26, 2020.

35. Vilsbøll T, Bain SC, Leiter LA, et al. Semaglutide, reduction in glycated haemoglobin and the risk of diabetic retinopathy. Diabetes Obes Metab. 2018;20:889-97.

36. Fadini GP, Sarangdhar M, Avogaro A. Glucagon-like peptide-1 receptor agonists are not associated with retinal adverse events in the FDA adverse event reporting system. BMJ Open Diabetes Res Care. 2018;6(1):e000475.

37. Okemah J, Peng J, Quiñones M. Addressing clinical inertia in type 2 diabetes mellitus: a review. Adv Ther. 2018;35:1735-45.

38. Barbosa CD, Balp M-M, Kulich K, Germain N, Rofail D. A literature review to explore the link between treatment satisfaction and adherence, compliance, and persistence. Patient Prefer Adherence. 2012;6: 39-48.

39. Yu M, Van Brunt K, Varnado OJ, Boye KS. Patientreported outcome results in patients with type 2 diabetes treated with once-weekly dulaglutide: data from the AWARD phase III clinical trial programme. Diabetes Obes Metab. 2016;18:419-24.

40. Suzuki S, Oura T, Takeuchi M, Boye KS. Evaluation of the impact of once weekly dulaglutide on patient-reported outcomes in Japanese patients with type 2 diabetes: comparisons with liraglutide, insulin glargine, and placebo in two randomized studies. Health Qual Life Outcomes. 2017;15:123.
41. Takase T, Nakamura A, Yamamoto C, et al. Improvement in treatment satisfaction after switching from liraglutide to dulaglutide in patients with type 2 diabetes: a randomized controlled trial. J Diabetes Investig. 2019;10:699-705.

42. Khunti S, Khunti K, Seidu S. Therapeutic inertia in type 2 diabetes: prevalence, causes, consequences and methods to overcome inertia. Therapeutic Adv Endocrinol. 2019;10:204201881984469.

43. Khunti K, Wolden ML, Thorsted BL, Andersen M, Davies MJ. Clinical inertia in people with type 2 diabetes: a retrospective cohort study of more than 80,000 people. Diabetes Care. 2013;36:3411-7.

44. Khunti K, Millar-Jones D. Clinical inertia to insulin initiation and intensification in the UK: a focused literature review. Primary Care Diabetes. 2017;11: 3-12.

45. Cavaiola TS, Kiriakov Y, Reid T. Primary care management of patients with type 2 diabetes: overcoming inertia and advancing therapy with the use of injectables. Clin Ther. 2019;41:352-67.

46. Russell-Jones D, Pouwer F, Khunti K. Identification of barriers to insulin therapy and approaches to overcoming them. Diabetes Obes Metab. 2018;20: 488-96.

47. Rubin RR, Peyrot M, Kruger DF, Travis LB. Barriers to insulin injection therapy. Diabetes Educ. 2009;35:1014-22.

48. Kruger DF, LaRue S, Estepa P. Recognition of and steps to mitigate anxiety and fear of pain in injectable diabetes treatment. Diabetes Metab Syndr Obes. 2015;8:49-56.

49. Iglay K, Hannachi H, Joseph Howie P, et al. Prevalence and co-prevalence of comorbidities among patients with type 2 diabetes mellitus. Curr Med Res Opin. 2016;32:1243-52.

50. Pantalone KM, Patel $\mathrm{H}, \mathrm{Yu} \mathrm{M}$, Fernández LL. Dulaglutide $1.5 \mathrm{mg}$ as an add-on option for patients uncontrolled on insulin: subgroup analysis by age, duration of diabetes and baseline glycated haemoglobin concentration. Diabetes Obes Metab. 2018;20:1461-9. 